\title{
UM REFLEXO, MUITAS FACES: NOTAS SOBRE A HISTÓRIA DA ADMINISTRAÇÃO DA JUSTIÇA E SEUS MECANISMOS NA VIA PENAL
}

\author{
Mário Luis Villarruel Silva ${ }^{1}$ \\ Ana Gabriela Mendes Braga ${ }^{2}$
}

\begin{abstract}
Resumo
Com o fito de discutir a administração da justiça penal, este trabalho parte da análise de registros policiais do Brasil Império. Para tanto, recorre, em específico, ao estudo multidisciplinar de processos criminais (manuscritos) mesonovecentistas; a metodologia comunga áreas como filologia, história, direito e antropologia, através da edição dessas fontes documentais. Interessa-nos aquilo que emerge de suas entrelinhas e que, como resultado, deslinda uma parte da constituição social da população daquele período, desvelando mecanismos da justiça em relação a algumas modalidades de violência de gênero, bem como da constituição dos dispositivos destinados ao controle e a ordem.
\end{abstract}

Palavras-chave: História; Administração da Justiça; Justiça Penal; Violência de Gênero; Agentes da Ordem.

\section{INTRODUÇÃO}

O presente trabalho visa apresentar reflexões sobre a promoção da justiça na aplicação do direito penal a partir da análise de constituição das instituições da justiça criminal em meados do Séc. XIX. Na esteira do mecanismo de operação da ordem e, tendo por base o contexto da antiga Província de Mato Grosso, hoje, Estado de Mato Grosso ${ }^{3}$, interessa-nos pontuar aspectos da administração judiciária e da profissionalização do operador do direito - enquanto elementos centrais na realização (ou não) da justiça nos pilares do Brasil Império.

Como fonte de pesquisa temos a edição semidiplomática de processos criminais mesonovecentistas, editados na Universidade de São Paulo/USP [2011] e capturados via imagens no Arquivo Público do Estado de Mato Grosso, onde se encontram arquivados na Série Penal - Cartório do 60 Ofício - sob as ordens

\footnotetext{
${ }^{1}$ Pesquisador do Núcleo de Antropologia do Direito da Universidade de São Paulo - NADIR/USP. Mestre em Filologia pela Faculdade de Filosofia, Letras e Ciências Humanas - Universidade de São Paulo - FFLCH/USP. E-mail: mariovillarruel@usp.br

2 Professora de Direito Penal na Faculdade de direito da Universidade Estadual Paulista "Júlio de Mesquita Filho" Unesp/Campus Franca. Doutora em Criminologia pela Universidade de São Paulo - USP. Pesquisadora do Núcleo de Antropologia do Direito da Universidade de São Paulo - NADIR/USP e do Instituto Brasileiro de Ciências Criminais - ICCRIM. E-mail: anagabrielamb@gmail.com

${ }^{3}$ Observe-se que Mato Grosso pertencia à Capitania de São Paulo, tendo se desmembrado em 1748, quando então deu início ao seu processo de estruturação administrativa (XAVIER, 2006, p. 23)
} 


\section{Defloramento; Estupro; Sumário de Culpa - Calúnia e Difamação .}

Pautados nas premissas de Nascimento (1988) e Chartier (1990), ao observarem as relações de práticas de leitura com objetos não apenas impressos - propomos uma abordagem transversal na interpretação do corpus, assim, os manuscritos de modo geral e, neste trabalho em específico, servem como suporte de visões muito além de históricas, mas sociais, econômicas, jurídicas e tantas outras quanto deles se puder extrair.

É preciso compreender não ser o manuscrito que fala, mas o/a pesquisador/a que o faz falar, nas palavras de Freire (2009), percebendo dimensões que transcendem o mero quadrante superficial das linhas grafadas, atingindo o contexto de produção dessas linhas, como anotado em Villarruel-Silva \& Mota (2015, pp.103-104).

Nesse sentido, interessa-nos buscar aquilo que nosso corpus tem a nos revelar, através da proposição de uma análise da estruturação - na Cuiabá mesonovecentista - daquilo que Clementino Sousa chamou de:

(...) ritual da vida, desenhando múltiplos quadros da cidade, que não aparecem nas obras de arte, nos romances e nos mapas, nesse tempo e espaço preciso, mas sim, nas ocorrências policiais, nos processos crime e nos relatórios dos chefes de polícia (2001, p. 03).

É à sombra das linhas e entrelinhas desses documentos processuais que esse cenário ganha lume, nele emerge a vida crua da sociedade do XIX. Estes processos nos ofertam condições de entender uma parte da constituição social da população daquele período, escapando das faustosas narrativas - em termos de Volpato (1987, p. 15) - como sói ocorrer na reconstrução historiográfica didaticamente contada.

\section{CONTEÚDO DOCUMENTAL, TIPO PROCESSUAL E MÉTODO}

Nos documentos analisados emerge a violência física praticada contra mulheres, grupo populacional, mesmo hoje, em boa parte, relegado à marginalidade social. São rasgos historicamente construídos que promovem o menoscabo de gênero desenhando um cenário seviciador quando analisado sob a sistemática das relações em que se configura essa violência (GREGORI, 2006, p. 256). O eixo de reflexão deste texto se vinculará à análise dos procedimentos da administração jurídica no que concerne esse tipo de processo, notas sobre a constituição histórica de mecanismos legais em contextos específicos da estrutura da via penal.

Considerando o contexto descrito, optamos por estruturar um trabalho de reflexão entre áreas transversais - humanas, sociais e jurídicas - a partir de linhas e perspectivas convergentes. Desse modo, esta proposta se inscreve numa esteira interdisciplinar com o fito de estabelecer um diálogo na proposição do estudo descritivo de um quotidiano próximo do real, configurando uma arqueologia de manuscritos, sendo estes, conforme Nascimento (1988, pp. 234-235), núcleos de tensões, produtos singularmente marcados e cujas marcas

\footnotetext{
${ }^{4}$ No campo filológico, denomina-se "ordem" a identificação que o/a arquivista dá às caixas ou latas em que acondiciona esse tipo documental. O material analisado foi transcrito e posteriormente editado segundo normas adaptadas no segundo seminário do projeto Para a História do Português Brasileiro PHPB realizado em Campos do Jordão - SP, em 1998. Cf. MEGALE \& TOLEDO NETO. Por minha letra e sinal: documentos do ouro do século XVII. Cotia: Ateliê, 2006.
} 
vinculam intencionalidades e situações humanas. Pensamos aqui numa etnografia do texto de pulso, recorrendo, assim, aos profícuos percursos conceituais surgidos do encontro entre a filologia, história e antropologia. Nos termos de Cunha, no trabalho arquivístico, os documentos são vistos como produtores de conhecimentos,

Não preservam segredos, vestígios, eventos e passados, mas abrigam marcas e inscrições a partir das quais devem ser eles próprios interpretados. Sinalizam, portanto, temporalidades múltiplas inscritas em eventos e estruturas sociais transformados em narrativas subsumidas à cronologia da história por meio de artifícios classificatórios (CUNHA, 2004, p. 292)

Nos marcos da Filologia ${ }^{5}$, optamos pelo exercício de sua Função Transcendente, definida, nas palavras de Segismundo Spina, como função em que o texto deixa de ser um fim em si mesmo da tarefa filológica, para se transformar num instrumento que permite ao filólogo reconstituir a vida espiritual de um povo ou de uma comunidade em determinada época. A individualidade ou a presença do texto praticamente desaparece, pois, o leitor, abstraído do texto, apenas se compraz no estudo que dele resultou. É importante observar, na sua função transcendente, a vocação ensaística do filólogo, em busca da história da cultura (1977, p. 77).

O processo de estudo e trato material se inscreve nesse marco teórico-metodológico ínsito à proposta de análise multidisciplinar. Nesse sentido, pelos limites próprios do formato artigo, nos é impossibilitada a apresentação integral de todas as edições ${ }^{6}$. Assim, exemplificaremos - na sequência - uma edição, um estrato de um processo integral e uma parte integrante do trabalho de pesquisa do qual se origina. Vide cabeçalho descritivo seguido de uma edição adaptada:

\begin{tabular}{|c|c|}
\hline \multicolumn{2}{|c|}{ MANUSCRITO. AUTOS CRIMES / PROCESSO - MANUSCRITO MARIA OLIVEIRA } \\
\hline \multicolumn{2}{|c|}{ Modalidade: Língua escrita; português técnico circunscrito ao meio jurídico-policial. } \\
\hline Tipo de Texto & Descritivo \\
\hline \multicolumn{2}{|c|}{$\begin{array}{c}\text { Datas do Documento: } 23 \text { de agosto; } 02-14-16-17 \text { e } 19 \text { de setembro; } 22 \text { e } 24 \text { de novembro, todas referentes } \\
\text { ao ano de } 1859 .\end{array}$} \\
\hline \multicolumn{2}{|c|}{$\begin{array}{l}\text { Assunto: Descrição de violência sofrida por Maria Oliveira, mulher jovem agredida com espada por seu } \\
\text { companheiro Manoel Jose A. de Souza (militar da Companhia de Pedestres). }\end{array}$} \\
\hline \multicolumn{2}{|c|}{ Local de Origem do documento: Cuiabá - Província de Mato Grosso. } \\
\hline \multicolumn{2}{|c|}{$\begin{array}{l}\text { Local de Depósito do documento: Arquivo Público do Estado de Mato Grosso - APMT. Série Penal. Cartório } \\
\qquad \text { do } 6^{\circ} \text { Ofício. }\end{array}$} \\
\hline Identificação do Autor & João Leocadio da Rocha. Escrivão. \\
\hline Edição & VILLARRUEL-SILVA, Mário Luis. \\
\hline
\end{tabular}

\footnotetext{
${ }^{5}$ Em sua concepção lato sensu, nas palavras de Santiago-Almeida (2009, p. 224), por ser a que se dedica ao estudo da língua em toda sua plenitude - linguístico, literário, crítico-textual, sócio-histórico etc. - no tempo e no espaço, tendo como objeto o texto escrito, literário e não literário (manuscrito e impresso).

${ }^{6}$ Os documentos integrais, bem como suas respectivas edições podem ser conferidos em VILLARRUEL-SILVA (2011) e/ou através do download < http://www.teses.usp.br/teses/disponiveis/8/8142/tde-25072011-155802/pt-br.php > 


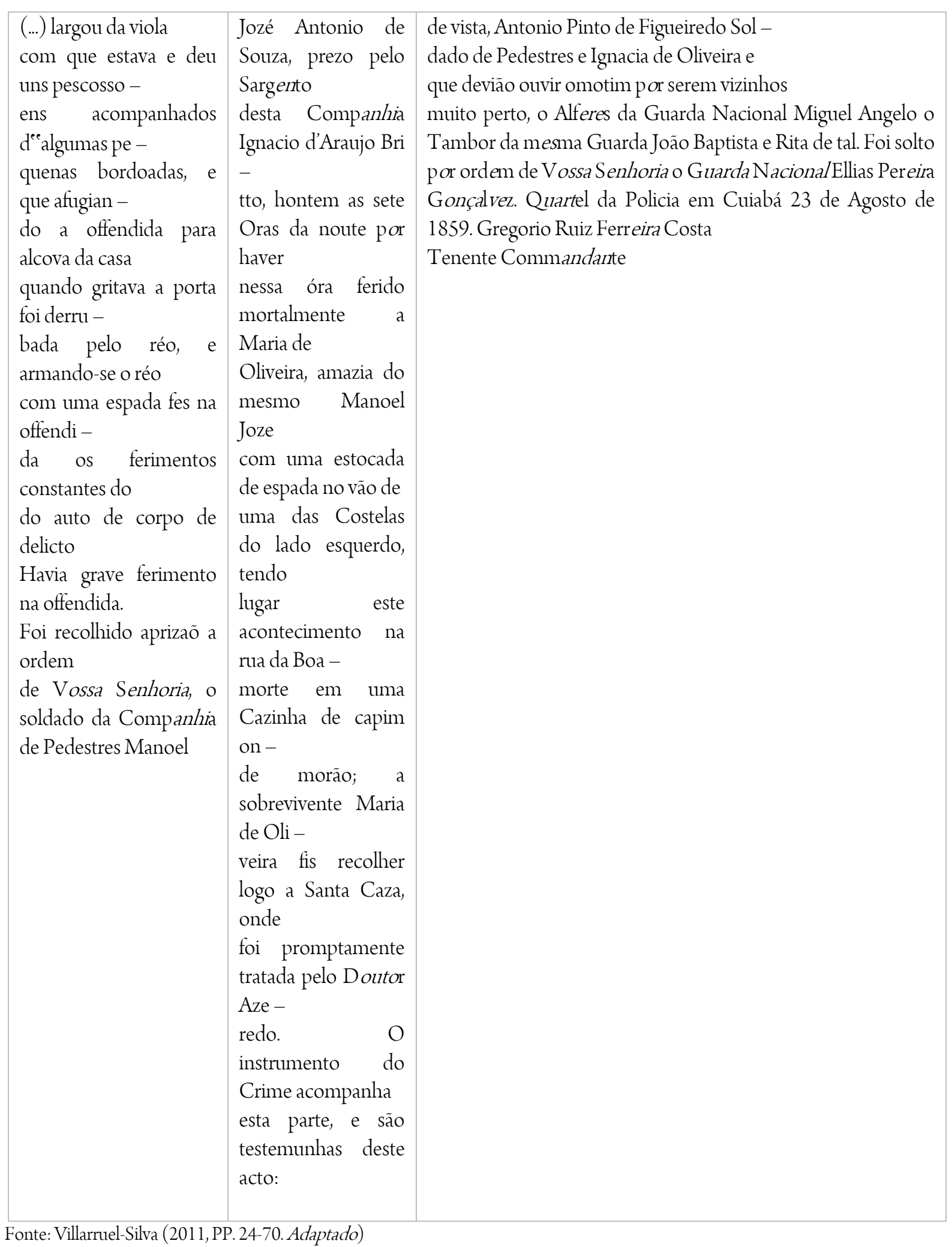

O estrato em questão demonstra o procedimento inicial prestado pelos operadores da ordem na Província de Mato Grosso. Apesar da amostra apresentada tratar de um caso de violência doméstica, as reflexões centrais visualizam algo como um mecanismo padrão, como notado nas minuciosas vistas dos arquivos naquele 
período e localidade, quanto ao procedimento daquelas delegacias quando deparadas com a violência contra mulheres 'do povo', pessoas comuns, aclarando que o eixo motriz destas reflexões, neste momento, não se filia estritamente às análises da violência de gênero, mas sim da administração da justiça em face a ela.

O amálgama da tríade entre pessoas comuns, violência e ordem escapa de uma tradição de tessitura factual, mesmo convergindo fatores primordiais na observação da história de um cotidiano simplificado, não menos merecedor de atenção quando comparado aos feitos de vulto histórico de determinada localidade (ARAUJO \& VILLARRUEL-SILVA, 2013, p.246)7 ; nas palavras de Perrot (1988) são incursões na vida daqueles excluídos da história. Wojciechowski (2004, p.02) entende que em um trabalho com essa perspectiva busca-se uma possível reconstrução das vivências 'comuns', para tanto é necessário tentar compreendê-las à luz de sua própria experiência e de suas próprias reações a essa experiência.

É o encontro das frestas que garantem suas sobrevivências (BURKE, 1992, p. 32), numa leitura cuja importância maior se oferta à construção da história a partir das pessoas ${ }^{8}$, para além da ideologia de um Estado, uma vez que muito da problemática do universo de pessoas comuns, simples ou do povo - em especial em cenários históricos de guerra - não se filia à obrigatoriedade de envolvimento revolucionário, como em organizações, corporações ou militâncias políticas, do contrário, podem se relegar à rotina de suas próprias vidas. Nas palavras de Wojciechowski (2004, p. 03), tratam-se centralmente de manifestações isoladas e aleatórias, de maneira a reclamar sua própria individualidade ou rejeitar aquilo que entrava o desenrolar de seu cotidiano.

\section{O SURGIMENTO DOS DISPOSITIVOS DE ORDEM}

No Brasil, data do início do século XIX a constituição dos dispositivos ostensivos que se destinariam ao controle de segurança social. A percepção do contexto de "desordem", numa constatação pragmática e ideológica e, diante de 'práticas adversas à ordem e à civilização', estabeleceu um controle rígido sobre hábitos e costumes. $\mathrm{O}$ que se denominou de "Movimento de Governamentalização do Estado Imperial Brasileiro" (2001, p. 20), configurou-se na premissa do eficiente controle daqueles que colocassem em perigo a tranquilidade e a paz no Império,

(...) com a criação de mecanismos de controle da vida, da morte e da mercadoria: através do esquadrinhamento das cidades; do controle da taxa de natalidade, nascimento de legítimos e ilegítimos; alimentação; moradia e, fundamentalmente, o controle da ordem (NOGUEIRA SOUSA, 2001, p. 20).

No entendimento macro da noção de formas de solução de conflitos e desordem, Tourinho Filho observa que, para que não ganhassem proporções dantescas - como de uma guerra - houve a necessidade de

\footnotetext{
${ }^{7}$ Importante conceber essas pessoas comuns, simples ou do povo como as não personalidades, cidadãos olvidados nos livros didáticos.

${ }^{8}$ Princípio fundamentado na Escola de Annales [1929], no eixo da relação entre a Historiografia e as Ciências Sociais (BARROS, 2010).
} 
atribuir-se a uma 'entidade' o julgamento e administração de casos de instâncias variadas, assim o Estado chamou a si e avocou a tarefa de administrar a justiça (2009, pp. 05-06). Nesse viés, uma série de mecanismos foram estruturados, dentre eles a criação de delegacias de polícia, no intuito de corroborar com uma eficiente administração do que se concebia por justiça e ordem.

Mato Grosso teve a instalação de sua primeira delegacia de polícia no ano de 1842. A partir desse período, é possível perceber documentalmente uma variabilidade de processos, ações de ordem múltipla com procedimentos que resvalam na noção concernente à justiça, ao direito e à lei.

Assim, a grande massa de homens, mulheres e crianças passou a sofrer intrusões, de forma direta ou não, em seu estilo de vida, no modo de organizar-se para produzir sua existência e suas relações (WOJCIECHOWSKI, 2004, p. 04).

Relações estas que passam a ser policiadas e vigiadas, para muito além de um contrato social punitivo, subliminarmente estabelecido nas relações de vivência em grupo, mas, neste caso, através de uma entidade com direcionamento específico e aparato de essência ideológica. Na chave teórica aportada por Michel Foucault (1999), esse período histórico corresponderia a consolidação da sociedade disciplinar na Europa, cujas instituições e práticas estavam voltadas ao governo da vida e a produções de subjetividades específicas: obedientes, úteis e controláveis.

A partir do Segundo Reinado, por volta de 1850, surge uma centralização político-administrativa expressa por uma estruturação de um sistema de controle social.

De fato, as instituições passaram a disseminar novos ideais acerca de comportamentos em relação à família, ao trabalho e aos poderes constituídos. Desse modo, aqueles que falavam em nome da nação a qual almejavam moderna, a elite imperial, definiam os papéis que caberiam a cada grupo social desempenhar na sociedade (WOJCIECHOWSKI, 2004, p. 05).

Nesse escopo, a população passa a introjetar valores de modernidade atrelados ao comportamento idealizado no pudor e nos 'bons costumes', o que vai de encontro com práticas comuns, concebidas, então, como turbulentas e de alto teor lascivo, como a rotina dos bares, praças, becos e mesmo certos lares ${ }^{9}$. Essa exacerbação de imoralidade, direcionada especialmente às classes menos abastadas, é também fruto de uma construção discursiva própria de um cristianismo frutífero.

É preciso observar, conforme Peraro (1997) haverem episódios de notória interferência da justiça eclesiástica no seio da justiça e da família e seu papel de ordenamento nesse período. A religiosidade transcendia o aspecto pessoal, estendendo-se aos ordenamentos legais.

As mudanças que caracterizaram esse período remodelaram os comportamentos individuais e intergrupais de modo a adequá-los às novas 'funções sociais' que caberiam a cada qual exercer, de forma

\footnotetext{
${ }^{9}$ Clementino Sousa observa que nos registros policiais do Mato Grosso mesonovecentista eram comuns designações como "famílias dadas à crápula" (2001, p.18), porém renuncia a essa denominação no intuito de indagar quem nomeia, especialmente pelo conteúdo criminal não transparecer vestígios concretos de determinadas práticas das famílias envolvidas.
} 
imprescindível se faz considerar esse ambiente sócio jurídico na constituição de nosso quadrante temporal de análise.

Como continuidade do processo de aperfeiçoar o controle sob certas populações, surge em 1871 a lei que reorganiza o judiciário:

Dotando-o de mecanismos à solução dos problemas advindos da violência privada e pública as quais exigiam mais contínua a presença dos aparelhos de vigilância e controle, o judiciário e a polícia na condução das negociações entre indivíduos, sociedade e Estado (RODRIGUES, 2008, p. 08).

A Lei 2033 sancionada em setembro de 1871, pela então princesa regente, Isabel de Orleans - em nome de D. Pedro II, rezava que seu regulamento "altera diferentes disposições da legislação judiciária". Alterava e instituía itens como: cargos, substituições, atribuições criminais, processos de prisões, processos de queixa e denúncia, pagamentos de fianças, recursos, habeas corpus, penalidades, atribuições e processos cíveis, dentre outros. Estas mudanças mantêm a pressuposição acerca de maiores cuidados investigativos e processos mais bem estruturados e que, em tese, se pautariam pela imparcialidade e revestiriam o processo criminal de garantias importantes para o acusado - ainda que o processo penal do Brasil Império possuísse forma estrutural simplificada, constituído de oitiva de testemunhas, acareação com réu (s) - e levantamento de provas quando não declarado o flagrante ${ }^{10}$.

Nos processos analisados, todas as medidas adotadas se estabeleceram conforme entendimento do condutor do processo, uma vez que na estrutura de investigação, o Inquérito Policial, que consiste nas diligências necessárias para descobrimento de fatos criminosos (TOURINHO FILHO, 2009, p. 198), apenas se formalizou no Brasil a partir de finais do século XIX, por meio do Decreto Lei No. 4824, de 28 de novembro de 1871. Em certa medida, sua formalização não exclui a possibilidade de já preexistirem mecanismos análogos adotados por operados da ordem aos quais competia o trabalho de investigação [ainda que 'instintivo'] de atos considerados criminosos nas Províncias.

\section{OPERADORES / AGENTES DA ORDEM: JUIZES, DELEGADOS E PROMOTORES NO MATO GROSSO DO XIX.}

De modo geral - em se tratando de Império brasileiro, quando do processo de consolidação formal dos aparatos que se destinariam ao controle social, o papel de repressor e julgador de ações tidas por criminosas ou que não atendiam a um comportamento social adequado, não possuía apenas uma figura central de referência, ao

\footnotetext{
${ }^{10} \mathrm{Na}$ estrutura de um processo penal no Brasil de hoje, um acontecimento infracional de ato contra pessoa evoca o Jus Puniendi, concretizado através do processo e surgido a partir da prática de uma infração penal. Nos elementos que desencadearão o processo, surge o Inquérito Policialque, nas palavras de Júlio Mirabete (2007, p. 56), é o elemento mais comum, embora não exclusivo, para que o fato indique infração penal e respectiva autoria.
} 
contrário, pulverizava-se em diversas figuras e instituições responsáveis por resguardar a moral da época ${ }^{11}$ :

professores, juízes, delegados e chefes de polícia, padres, presidentes das províncias, entre outros, através de suas funções públicas representando suas respectivas instituições, passaram a coibir os comportamentos sociais vistos como inadequados a um país com vias ao progresso (WOJCIECHOWSKI, 2004, p. 04).

Na Província de Mato Grosso, instalou-se a primeira Secretaria de Polícia em 1842, durante o governo de Miranda Reis. A partir desse acontecimento foi necessária a nomeação e contratação de profissionais oriundos dos centros do país para atuação nessas localidades. Esses profissionais interessavam-se pelo ofício em terras distantes, especialmente pelo status a ser conquistado, bem como pelos 'retornos' que lhes seriam invariavelmente prestados pela elite local, comerciantes e proprietários rurais,

sobretudo, os cargos administrativos, impondo através das redes clientelares, aos grupos menos privilegiados na hierarquia social, relações pautadas por interesses individuais que se fundavam em concepções de civilização e ordem postulados pelo liberalismo idealizado pelos bacharéis, na sua maioria filhos e apadrinhados dos coronéis políticos da região (RODRIGUES, 2008, p. 04).

Para Wolkmer (1999) a ordem burguesa emanava de um sistema jurídico marcado por princípios liberais de bacharéis engajados na legitimação de seu discurso enquanto "benfeitores" de um progresso em vias de se estruturar. Esses profissionais tinham sua formação - em grande parte - na Província de São Paulo ${ }^{12}$.

Os profissionais que chegavam a Mato Grosso para tratarem da "justiça" eram comumente inexperientes, faltava estrutura administrativa adequada e pessoas habilitadas para exercerem certos cargos como de juiz de direito (NOGUEIRA SOUSA, 2001, p. 25). A burocracia jurídica e policial lidava no dia a dia com formas diferentes de conflitos, estando expostos às tensões surgidas de situações inesperadas, assim, homens despreparados na execução de determinadas ordens perdiam o controle da situação, transformando réus em vítimas e vice-versa (RODRIGUES, 2008, p.03).

O primeiro Chefe de Polícia de Mato Grosso foi José da Costa Leite Falcão, advogado cuiabano, formado na Província de São Paulo, conforme Nogueira Sousa (2001, p. 46); a partir de sua nomeação e instituição oficial da Secretaria de Polícia, inicia-se um processo de produção de relatórios, ocorrências, ofícios, cartas e documentos afins. Conforme visualizado no manuscrito arquivado sob a ordem "documentação avulsa" (Arquivo Público de Mato Grosso, Secretaria de Polícia, Lata A - 1843) a estrutura dessa Secretaria deveria ser constituída por um chefe de polícia, um delegado, um subdelegado e um inspetor de quarteirão.

As funções de cada agente constituinte dessa estrutura se direcionava a controlar, vigiar e esquadrinhar a

\footnotetext{
${ }^{11}$ Tal difusão também pode ser observada em períodos recentes, principalmente nos interiores do país. Nos dias de hoje esse movimento evidencia-se principalmente com a presença de líderes ligados às igrejas pentecostais no Congresso Nacional. Cf. NATIVIDADE, Marcelo Tavares. Margens da política: direitos sexuais, Estado e religióes. Rio de Janeiro: Garamond, 2015.

${ }^{12}$ Leia-se Faculdade de Direito do Largo de São Francisco, atual Faculdade de Direito da Universidade de São Paulo - USP. Conforme Araújo et al (2007) a dimensão da influência dessa faculdade como formadora da intelligentsia do Brasil pode ser medida pela abrangência das posições civis alcançadas por seus alumni: no Império, senadores, deputados, ministros, presidentes de Províncias entre tantos outros.
} 
cidade em distritos e quarteirões, usando-se de regulamentos, relatórios, estatísticas de crimes e inspeções em lugares públicos. De modo oficial, nas palavras de Figueiras Junior $(1874)^{13}$, esses agentes tinham por função obrigar a assinar o termo de bem viver aos vadios, mendigos, bêbados por hábito, prostitutas que perturbavam o sossego público e turbulentos que, por palavras e ações, ofendiam os bons costumes, a tranquilidade pública e a paz das famílias. O que preludiava um cenário de concepção criminológica que se arrastaria até os dias de hoje.

A criminologia no Brasil, como conhecimento voltado para compreensão do homem criminoso e para o estabelecimento de uma política científica de combate à criminalidade, será vista pelas elites como um instrumento essencial para a viabilização dos mecanismos de controle social necessários à contenção da criminalidade no país. Mas, com a proclamação da República, os desafios colocados para as elites republicanas não irão se limitar apenas ao estabelecimento de novas formas de controle social, mas incluirão especialmente o desafio ainda maior de consolidar os ideais de igualdade política e social do novo regime em face das particularidades históricas e sociais da situação nacional (ALVAREZ, 2006, p. 142).

É necessário entender que todos os envolvidos nas malhas da justiça, em expressão de Marinete Rodrigues (2008b), posicionavam-se de modo contumaz em situações quando da conveniência e vantagens às suas relações nos campos sociais e pessoais. Para a pesquisadora, ainda, Mato Grosso constituía uma sociedade cujo peso das hierarquizações administrativas estava intimamente ligado à força política e jurídica dos grupos sociais próximos ao poder central.

Toda uma estrutura político-jurídica nessa consolidação local visava à sustentação de um projeto de imagem de civilidade e progresso à Mato Grosso, legitimando, com isso, o pleno exercício de poder que:

(...) unia de um lado todos os súditos ao Imperador, desde o mais pobre dos cidadãos da mais distante freguesia do 'Sertão' até o senador do Império ou os conselheiros do Estado; e ligava, de outro, cada um dos homens livres tanto aos que se encontravam acima quanto os que se encontravam abaixo da escala hierárquica, por meio de lealdades e fidelidades, gerada por um processo cumulativo de favores e encargos (MATOS, 2004, p. 164).

A unidade e solidificação de um Império eram 'palavras de ordem' na estrutura de uma entidade de perfil social. Desde o fim da Guerra do Paraguai, tornou-se marcada a divisão jurisdicional, tornando-se presente nas Comarcas da Província todo o aparato legal de juízes, promotores e seus tribunais.

Em Mato Grosso, o ano de 1871, marcou a reorganização das estruturas jurídicas, políticas e econômicas [...] ação que demandou ocupação do espaço geográfico, regulação das atividades jurídicas, a burocracia administrativa e a retomada do crescimento (RODRIGUES, 2008, p.03).

Era ímpeto 'generalizado' alcançar localidade próspera e além-barbárie, nesse sentido buscou-se um equilíbrio entre autoridades e população, através da regulação de comportamentos que se operava, dicotomicamente, em dois sentidos ${ }^{14}$, de um lado a sociedade cobrava posturas e atitudes condizentes com o status de ordem e civilização, de outro a própria delegação de autoridade a um grupo privilegiado do Estado,

\footnotetext{
${ }^{13}$ Cf. Código do Processo do Império do Brasil. Tomo II. Rio de Janeiro: Eduardo e Henrique Laemmert, 1874.

${ }^{14}$ Op. Cit.p.03.
} 
gerava antagonismos entre os indivíduos e seus grupos sociais ${ }^{15}$.

É preciso entender, no entanto, a presença marcante de conflitos nas esferas da própria lei. A sutileza dos vínculos de leniência de certos casos demonstra a fragilidade dessas relações, configurando novos modelos de mediação de poder. Essas características estão relacionadas com a forma de constituição da futura República no Brasil, que segundo Marcos Alvarez (2003, p. 243) conciliou o "discurso desigual da criminologia com o liberalismo não democrático dos bacharéis". Tal arranjo histórico permitiu, a partir da articulação dos campos da lei e da norma, que, longe da igualdade proclamada pelo discurso jurídico, houvesse tratamento jurídico-penal diferenciado para determinados setores da população, além do estabelecimento de critérios diferenciados e hierarquizados de cidadania (2003, p. 30).

Uma das formas que se sobrepunham às exigências republicanas era o poder do coronelismo, o qual podia estabelecer sua autoridade sempre que sentida a necessidade. Na prática, aqueles que ocupavam os cargos nos escalões mais altos do governo, local e central, exerciam com predomínio a autoridade e as lideranças na resolução dos conflitos policiais, jurídicos e políticos. A conservação do 'sossego' dos grandes latifundiários não sofre mudança no país desde o período colonial quando se instaurou a manutenção do poder relegado a esse grupo $^{16}$.

\section{OPERADORES / AGENTES DA ORDEM: POLÍCIA E EXÉRCITO - BREVES CONSIDERAÇÕES.}

Entre os operadores da ordem desde o século XIX, estão os militares [leia-se exclusivamente o Exército] e a Polícia [a priori, genericamente, assim denominada], havendo por vezes um resvalar conceitual e mesmo terminológico quando do tratamento histórico (documental) de ambas instituições. O que hoje é uma conhecida divisão entre as chamadas Forças Armadas [exército, marinha e aeronáutica] e Forças Auxiliares [polícias em suas variadas modalidades] - um século e meio atrás ainda carecia de melhores definições de atuação e finalidades ${ }^{17}$.

Os manuscritos que respaldam este trabalho lidam essencialmente com operadores da ordem pertencentes ao quadro militar do Exército da Província de Mato Grosso, à época era a essa entidade relegada, ao menos oficialmente, a função de policiar o cotidiano local. Na estrutura dos processos correntes entre 1858 e

\footnotetext{
${ }^{15}$ Essas relações acabaram por gerar conflitos e certo clima de "anarquia" por parte daqueles que se opunham aos grupos políticos no poder. Cf. PALERMO, Miguel. Nioaque: evolução política e revolução de Mato Grosso. Campo Grande: Tribunal de Justiça de Mato Grosso, 1992.

${ }^{16}$ Cf. Maria Isaura Pereira Queiroz. O mandonismo local na vida política brasileira e outros ensaios. São Paulo: Alfa-Omega, 1976.

${ }^{17}$ Atualmente entre as polícias brasileiras encontramos atuações marítimas, aéreas e terrestres. Podem ser ostensivas ou secretas, leigas ou de carreira e, diferenciadas especialmente quanto a seus objetos de atuação. Temos a Polícia Federal, com encargos exclusivamente voltados ao âmbito de interesse nacional (secreta e de carreira); Polícia Civil, com a finalidade de investigar infrações penais e apurar respectiva autoria, de forma complementar à Polícia Militar, que visa à profilaxia do crime de forma ostensiva.
} 
1878 encontram-se designações alternantes entre “Secretaria de Polícia”, “Delegacia de Polícia” e “Quartel”, o que referenda essa factual oscilação entre categorias militares (VILLARRUEL-SILVA, 2011); Cuiabá, especialmente, conforme Volpato (1993) era uma cidade evidentemente militar [Exército] e possuía um elevado contingente.

Em se tratando de um conceito de Polícia, pertinente se faz ponderar ter sua gênese no princípio do Séc. XIX, quando da oficialização do Estado brasileiro como gestor da justiça e do controle social, já numa tentativa de diferenciação com o Exército, porém, ainda oscilando na atribuição de funções entre ambos.

Tourinho Filho (2009) observa que a 'Polícia' [Do Grego = Politeia = algo como governo da cidade] ganhou ressignificações desde seu entendimento inicial e, a partir do surgimento dos aparatos de aplicação de ordem, é a que evoca os pareceres mais variados na população, dentre aspectos que vão de seu método à idoneidade dubitável.

David Bayley (2001, p.20) identifica a polícia com pessoas autorizadas por um grupo para regular as relações interpessoais dentro deste grupo através da aplicação de força física. $\mathrm{O}$ autor estabelece três elementos que ajudam a reconhecer a unidade histórica da polícia como instituição: uso da força física, a ser usada internamente ao grupo social e a partir de uma autorização coletiva, ou seja, "presa a unidades sociais das quais deriva sua autoridade" (BAYLEY, 2001, p. 20). Já a polícia como uma instituição moderna, instituída a partir do sec. XX, é caracterizada pelo autor a partir de outros três elementos: natureza pública, especialização e profissionalização, os quais serão agregados a noção histórica da instituição.

Para Spagnol (2001) a polícia está muito além de alcançar sua imagem e realizar sua função de agente de segurança idônea e confiável ${ }^{18}$. Marinete Rodrigues (2008) observa que, na Província de Mato Grosso, a postura dos agentes de segurança, policiais/militares, tal como nos dias de hoje,

(...) percebia-se que o exercício da violência física não era uma prerrogativa dos prováveis delinquentes, os representantes do Estado também recorriam à violência quando não conseguiam dominar determinadas situações (RODRIGUES, 2008, p. 08).

Em démarche da construção histórica, é valido ressaltar que, conforme aponta Adorno (1995, p. 300) existe uma relação entre violência e tradição na sociedade brasileira. Historicamente, a violência esteve incorporada de modo regular ao cotidiano de homens livres, libertos e escravizados, apresentando-se, via de regra, como solução para os conflitos sociais e o desfecho de tensões nas relações intersubjetivas. O que ora se pontua, está no fato de o polo encarregado ao controle da violência também recorrer no mesmo procedimento, então, coibido.

Provável que não fosse realidade apenas em Mato Grosso, mas no Império como um todo, porém, os processos esclarecem pontos quanto aos métodos e procedimentos da aplicabilidade da justiça em localidades recônditas, como poderá ser mais bem contextualizado na sequência.

\footnotetext{
${ }^{18}$ ADORNO (2002) observa que no crescimento da criminalidade no Brasil há de se atentar às violações dos Direitos Humanos, dentre eles mortes praticadas por policiais em confronto com civis.
} 


\section{A JUSTIÇA E SUA APLICAÇÃO}

A justiça era, e ainda é, status por ser alcançado. É preciso ressaltar que a noção de Justiça é anterior ao direito e ao estabelecimento de leis formais, para tanto, esta Justiça está para muito além do conceito que a atrela a todo um mecanismo jurídico estabelecido. Logo, naquele período, conhecia-se uma teoria de justiça, bastante peculiar ao seu tempo e espaço de consolidação. Rodrigues (2008) aponta que os procedimentos a que se chegava à justiça se davam pelo dispositivo policial regido por uma ordem moral.

Atitudes que nas práticas do dia-a-dia redefiniam os contornos e o entrelaçamento das relações sociais, as quais modificavam os modelos de inocência e culpa estabelecidos pelo conjunto de códigos legais, morais e simbólicos (RODRIGUES, 2008, p. 01).

$\mathrm{Na}$ documentação analisada, em princípio, o modelo de culpabilidade nos quadrantes legais e morais parecia aplicado com justeza, porém o modelo simbólico, aquilo que está para além da convenção textual da lei que subjaz grande parte dos processos, traz à tona o juízo ideológico no procedimento. É preciso compreender que mesmo a lei sendo aplicada de modo "justo", havia meandros perceptíveis nas entrelinhas dos processos, podendo vir à tona uma relação dicotômica entre membros do judiciário e a interpretação das leis.

É possível inaugurar tal veio reflexivo quando da interpretação do denominado princípio da legalidade em "não haver crime, ou delicto (palavras synonimas neste Código) sem lei anterior que o qualifique"19, o que denota uma compreensão estanque do que se concebia por crime e/ou ato criminoso, excetuando - ao menos codicilarmente - a subjetividade de atos não circunscritos nos quadrantes desse texto legal.

No estudo de casos aos que incursionamos para tecer estas considerações, faremos aportes pontuais dando lume a momentos específicos da estrutura processual. São três processos crime datados de 1858, 1859 e 1878 que dão suporte ao percurso histórico judicial aqui traçado. Apresentamos, a seguir, seus respectivos sumários processuais e breves incursões em pontos cruciais ao endosso fático de determinados elementos constituidores da administração da justiça na via penal do Brasil Império.

\section{PROCESSO $01=$ MANUSCRITO 01}

\section{Manuscrito. Autos Crimes.}

Modalidade: Língua escrita; português técnico circunscrito ao meio jurídico-policial.

Tipo de Texto: Descritivo.

Data do Documento: Processo policial - documento estruturado em datas diferentes, sendo elas, respectivamente: 23 de agosto; 02 - 14 - 16 - 17 e 19 de setembro; 22 e 24 de novembro, todas referentes ao ano de 1859 .

Assunto: Descrição acerca de violência sofrida por Maria Oliveira, mulher jovem agredida com espada por seu companheiro Manoel Jose Antonio de Souza (militar da Companhia de Pedestres).

Local de origem do documento: Cuiabá - Província de Mato Grosso.

Local de depósito do documento: Arquivo Público do Estado de Mato Grosso - APMT. Série Penal. Cartório do

${ }^{19}$ Cf. Código Criminal do Império do Brazil. No Edição. Revisada por Jose Marcellino Pereira Vasconcellos. Rio de Janeiro: 1860. Disponível em Harvard University - Harward Law Library. Biblioteca Digital. Acessado em 28/05/2010. 


\title{
$6^{\circ}$ Ofício.
}

Identificação do autor: João Leocadio da Rocha. Escrivão.

\section{PROCESSO $02=$ MANUSCRITO 02}

\author{
Manuscrito. Autos Crimes. \\ Modalidade: Língua escrita; português técnico circunscrito ao meio jurídico-policial. \\ Tipode Texto: Descritivo. \\ Data do Documento: Processo policial - documento estruturado em datas diferentes, sendo elas, \\ respectivamente: $08-09-10-11$ e 13 de fevereiro de 1858 . \\ Assunto: Descrição acerca de violência sofrida por Blandina Maria, mulher jovem agredida, aparentemente sem os \\ motivos claros, por outra mulher, Maria das Dores. \\ Local de origem do documento: Cuiabá - Província de Mato Grosso. \\ Local de depósito do documento: Arquivo Público do Estado de Mato Grosso - APMT. Série Penal. Cartório do \\ $6^{\circ}$ Ofício. \\ Identificação do autor: Antonio Pinto Botelho. Escrivão.
}

\section{PROCESSO 03 = MANUSCRITO 03}

\section{Manuscrito. Autos Crimes.}

Modalidade: Língua Escrita; português técnico circunscrito ao meio jurídico-policial.

Tipode Texto: Descritivo.

Data do Documento: Processo policial - documento estruturado em datas diferentes, sendo elas, respectivamente: 16 - 18 - 19 e 20 de setembro de 1878 .

Assunto: Descrição acerca de violência sofrida pela Escrava Maria, mulher menor de idade violentada e agredida por Manoel Maximo, tendo como comparsa, seu amigo, Floriano Neves.

Local de origem do documento: Cuiabá - Província de Mato Grosso.

Local de depósito do documento: Arquivo Público do Estado de Mato Grosso - APMT. Série Penal. Cartório do $6^{\circ}$ Ofício.

Identificação do autor: Antonio Pinto Botelho. Escrivão.

No processo identificado como 01 (1859) - Fólio 14 - é citado o Artigo 205 do Código Criminal do Império pelo qual o Delegado Antonio Romualdo da Silva Pereira enquadra Manoel Jose Antonio de Sousa, acusado pelo crime de agressão e ferimento grave contra Maria Oliveira (processo este que tratamos nas páginas iniciais deste texto). Nesse artigo prescreve-se que "Se o mal corporeo resultante do ferimento ou da offensa physica produzir grave incommodo de saude ou inhabilitação de serviço por mais de um mez"20, o acusado deve ser detido e a vítima abstida do trabalho, conforme se orientou proceder à época.

Nesse caso, a vítima está concebida como 'amasia' de Manoel José, 45 anos, soldado da companhia de pedestres, seu agressor. A vida conjugal estabelecida nesse molde, aos olhos da moral não mereceria tratamento oficial nos procedimentos legais, como percebido na amenização da agressão no "Auto de Sanidade" procedido na vítima algumas semanas após o ocorrido.

Nesse auto os médicos Francisco Antonio d'Azeredo e João Adolpho Josetti avaliam o estado da 
paciente como positivo, estando 'tudo foi mui favoravelee (Fólio 14 - linhas 5 e 6 ) e, diante disso, diminuem o valor da indenização a ser paga. Nesse contexto, podemos apontar alguns mecanismos perpetuadores de (in) justiças: i) o julgamento da culpabilidade do autor é permeado pela moralidade e oficialidade da relação amorosa: ii) a afirmação da sanidade legítima à violência de gênero ao enquadrá-la dentro da normalidade do agressor.

Nesse mesmo processo cita-se por cinco vezes o Artigo 294 - Fólios 06v; 07; 08; 09 e 12 v- porém não é mencionado seu 'diploma' legal, apenas é informado pelo escrivão Joaquim José de Carvalho tratar-se de um Artigo referente a um Registro de 31 de janeiro de 1842. É possível que se trate de um artigo interno da Secretaria de Polícia de Mato Grosso, uma vez que sua datação condiz com a inauguração, além do fato de não haver um procedimento padrão no processo de investigação no Império e, na evocação de tal artigo haver sempre correlação com a oitiva de testemunhas.

No processo identificado como 02 (1858) - sobre a violência sofrida por Blandina Maria, mulher jovem agredida, aparentemente sem os motivos claros, por outra mulher, Maria das Dores, no Fólio 02 são mencionados três Artigos do Código Criminal do Império. O primeiro, Art. $2^{\circ}$, prescreve que "julgar-se-há crime ou delicto: $₫ 2^{\circ}$ a tentativa do crime, quando for manifestada por actos exteriores, e princípio de execução, que não teve effeito por circunstancias independente da vontade do delinquente" ${ }^{21}$. Nesse caso, a vítima apenas conseguiu se salvar de agressões maiores devido à ajuda de terceiros, salvo isto, poderia haver consequências graves, no entanto, seu auto de sanidade direciona o julgamento a compreender que, estando a vítima procedendo em boa recuperação, isentar-se-ia de culpa - de modo anverso ao prescrito no Código - a agressora que ora se apresenta. Esse estrato aponta para uma relativização do dano, ignorando os aspectos emocionais e psíquicos envolvidos, e minimizando a responsabilidade da autora pela agressão.

No processo identificado como 03 (1878) - aparece a descrição acerca da violência sofrida pela Escrava Maria, mulher menor de idade (16 anos) violentada e agredida por Manoel Maximo, tendo como comparsa, seu amigo, Floriano Neves. Os agressores são enquadrados pelo Delegado, em princípio, por crime inafiançável, não sendo mencionado o artigo e parágrafos ilustrativos no Código Criminal do Império ${ }^{22}$. Em primeira instância o tratamento dispensado à Maria parece ser consoante com a noção de aplicação de justiça. Porém, como ponderado nas palavras de Rodrigues (2008) ao frisar disparidades entre aplicadores e interpretação das leis, esse processo ilustra o desnível de sua condição escrava.

O delegado entendeu serem os agressores culpados, porém, foram absolvidos pelo juiz. Segundo seu

\footnotetext{
${ }^{20}$ Cf. Código Criminal do Império do Brazil. Nova Edição, Revisada por Jose Marcellino Pereira Vasconcellos. Rio de Janeiro, 1860, p. 78. Disponível em Harvard University - Harvard Law Library. Biblioteca Digital, acessado em 28/05/2010.

${ }^{21}$ Op. Cit. p. 06.

${ }^{22} \mathrm{O}$ atual código penal brasileiro enquadra o estupro como crime tipificado no artigo 213. Existindo toda uma estrutura interpretativa sobre o ato que perpassa, ainda, os artigos 213,214,217a, e mesmo o Art. 61 da Lei de Contravenções Penais, no que compete estupro de vulnerável e concepções sobre atos libidinosos.
} 
entendimento, não havia provas de que Maria fosse menor de idade. A posição social de Maria que, além de mulher, era escrava, deslocava a possibilidade de constituir-se vítima, sujeita de direito, portadora de dignidade e merecedora da proteção penal. O deslocamento do processo para a temática da maioridade da vítima e não do ato praticado contra ela demonstra os mecanismos sutis em ação dentro do próprio sistema de justiça criminal perpetuadores de desigualdades sociais.

Ademais, uma figura fundamental à acusação era a escrava Magdalena que, conforme o processo integral foi testemunha da agressão sofrida, de todo modo, na narrativa documental foi relegada à categoria 'informante', diminuindo assim seu status e o peso de suas palavras no âmbito da apuração criminal:

Nesse sentido, as relações conflituosas que desencadearam a violência foram orientadas por normas assentes nos costumes de dominação e sujeição do mais fraco socialmente pelo mais forte simbolicamente (RODRIGUES, 2008, p. 07).

Marinete Rodrigues (2013), ao analisar processos de mulheres comuns ocorridos ao sul da Província, hoje, Mato Grosso do Sul, constata que muitos dos casos de violência subjazem à própria narração do processo. Neste caso, no processo da Escrava Maria, a resolução da violência evoca outros níveis de violência, escamoteada nas entrelinhas do tratamento dispensando ao ocorrido. Não perdendo de vista a recorrência de casos, como apontados por Fausto ${ }^{23}$ (1984) quando a vítima se torna ré e vice-versa, denotando a morosidade e truculência de uma justiça nada interessada em perder seus vínculos com sua elite mantenedora, como latifundiários e escravocratas.

Todos os processos aqui analisados estão sob uma compreensão de crime e criminoso intimamente ligada à definição de 1830, definição esta unívoca, sem prerrogativas ou possibilidades de compreensão da subjetividade dos atos julgados, cujos desdobramentos reflexivos facilitariam um intento de alcance à tão sonhada justiça. Premente se faz ponderar serem estas concepções frutos de seu tempo de produção, logo, contextuais. O que aqui é posto à baila se debruça sobre uma espécie de legado atávico penal em face às poucas mudanças ocorridas no seio da justiça criminal. Como uma área legal pode proceder de modos tão análogos por tantas décadas? É um questionamento que assombra profissionais da segurança pública, cuja resposta pode até ter sido elucidada, mas cuja mudança efetiva dessa espécie de cultura penal parece distante.

Como elemento final neste nosso percurso, é pertinente frisar que estamos atribuindo aos registros policiais analisados o status de 'inquérito', devido exclusivamente à sua estrutura, mas não à sua formalidade, uma vez que são constituídos de Termos de Assentados, Certificações, Remessas, Conclusões e Indenizações.

No processo de persecução criminal - conforme frisado - o inquérito surge em 1871 [Decreto 4824 de 22 de novembro de 1871], e é fato não ser garantia total de colheita de provas, de todo modo, figura como instrumento importante na estrutura de investigação. O inquérito surge no universo jurídico através do Direito Germânico, sua estrutura é herdada pelo ocidente e dá base a estruturas legais contemporâneas. 
No inquérito encontramos os 'autos', pré-existentes à própria criação da estrutura de inquérito e que, no rol histórico dos registros policiais, emerge como ponto basilar na promoção da justiça. $\mathrm{O}$ auto pode ser formalmente definido como ato realizado para cumprir um imperativo legal ou ordem de autoridade constituída. Importante se faz problematizar o status de regente processual que o documento recebe, como nos casos analisados, em que foram preponderantes para inocentar ou condenar os réus. Neste trabalho, encontramos suas seguintes variedades 'Autos de Perguntas e Respostas'; 'Autos de Corpo de Delito'; 'Autos de Sanidade' e 'Autos de Qualificação'.

Nesses pontos de análise, o que constatamos recai sobre um protocolar mecanismo de coleta de dados. Perguntas deveriam ser respondidas, no entanto, seu uso na investigação como um todo, se revestia de um tecnicismo movediço, uma vez que muito do que se questiona, evoca [e/ou pode evocar] tanto inverdade de respostas, contextos específicos de respostas [motivados por medo/raiva] e outros aspectos. No percurso de todas as investigações editadas, em momento algum emergiu tal preocupação, alijando os processos de uma resolução mais factível que imaginária.

\section{CONCLUSÕES OU O QUE SE TEM POR CONSIDERAR}

Os dispositivos legais que, atualmente, se destacam como recorrentes em nossos processos penais, no passado procediam num peculiar sentido de justiça, construída de modo nem tão igualitário, como se pretendia. Os mecanismos dessa mesma justiça se modificaram, ganharam novas roupagens e estruturas mais eficazes, porém, muitos vácuos foram deixados no passado e muitas pessoas, com isso, prejudicadas.

É importante frisar que, o sistema de justiça criminal atual ainda reflete as muitas faces historicamente construídas. São ressonâncias vinculadas aos muitos aspectos de procedimentos que no Brasil ainda são utilizados, como dezenas de anos atrás, perpassando um pueril engano de uma profícua via penal dedicada ao desvendar de crimes de maneira assertiva e isenta, o que fatalmente recai em suas muitas falhas e problemas estruturais. É perpassada a impressão de um constante atraso estrutural em nossas adoções teóricas quando lidamos com a ultima ratio, configurando um quadro de constantes questionamentos, aparentemente este atraso está impregnado a uma cultura penal solidificada desde os primórdios de seu surgimento como recurso de ordem social.

Tendo como pano de fundo processos mesonovecentistas, nos foram possibilitados entendimentos de meandros sociais, históricos, jurídicos e tantos outros que surgirão a partir de abordagens que novos pesquisadores/consultores tomarão. O método filológico, em sua perspectiva transcendente, somada à revisão bibliográfica paralela aos processos, trazem à tona detalhes e indícios de um confim brasileiro, cujo cotidiano e

${ }^{23}$ Cf. FAUSTO, Boris. Crime e Cotidiano em São Paulo (1880 - 1924). São Paulo: Brasiliense, 1984. 
rotina de violência, especificamente contra mulheres, parece ser inesperado no período circunscrito, salvo pelos grandes acontecimentos, como guerras e contentas em níveis nacionais já historicamente registrados.

Em perspectiva sociohistórica, análises de processos de constituição paulatina em variadas localidades, recebem sempre seus méritos descripcionais, no instante em que, ao colaborarem na melhor compreensão do passado, consequentemente, dão recursos para melhor se planejar o futuro.

\title{
A REFLECTION, MANY FACES: NOTES ON THE HISTORY OF ADMINISTRATION OF JUSTICE AND ITS MECHANISMS IN CRIMINAL ROUTE.
}

\begin{abstract}
Aiming at discussind the administration of criminal justice, this paper analyzes Brazilian police records from the time of the Empire. In order to do so, it draws attention, in particular, to a multidisciplinary study of manuscripts of criminal cases of the mid-nineteenth century. The methodology used in this study shares concepts from philology, history, law and anthropology by editing these documentary sources. We are interested in what emerges from the subtext of these data and which, as a result, reveals a part of the social constitution of the population of that period unveiling the mechanisms of justice related to some modalities of gender violence as well as the establisment of devices designed to maintain control and order.
\end{abstract}

Keywords: History; Justice Administration; Criminal Justice; Gender Violence; Agents of Order

\section{BIBLIOGRAFIA}

ADORNO, Sérgio. Crime e violência na sociedade brasileira contemporânea. Jornal de Psicologia-PSI, n. Abril/Junh, p. 7-8, 2002.

A violência na sociedade brasileira: um painel inconcluso de uma democracia não consolidada. Revista Sociedade e Estado. Universidade de Brasília - UNB. Volume X, no 02 julho a dezembro de 1995.

ALVAREZ, Marcos César. Bacharéis, Criminologistas e Juristas: Saber Jurídico e Nova Escola penal no Brasil. São Paulo:IBCCRIM, 2003.

Apontamentos para uma história da criminologia no Brasil. História da Justiça Penal no Brasil: pesquisas e análises. IBCCRIM: São Paulo, 2006.

ARAUJO, Gabriel Antunes et al. Alguns manuscritos do século XIX da Faculdade de Direito da Universidade de São Paulo. Cosmica (Kyoto-Japão. 1971), v. 37, p. 143-179, 2007.

ARAUJO, Gabriel Antunes \& VILLARRUEL-SILVA, Mário Luis. Mulheres e Contextos de violência em narrativas penais da Província de Mato Grosso. Caderno Espaço Feminino - UFU: Uberlândia-MG. v 26, n.1 jan./jun. 2013.

BARROS, José D. A Escola dos Annales e a crítica ao historicismo e positivismo. Revista Territórios e Fronteiras. V.03. N.01. Cuiabá-MT.Jan/Jun. 2010. 
BAYLEY, David. H. Padrões de policiamento: Uma análise comparativa internacional. São Paulo: Editora da Universidade de São Paulo, 2001.

BURKE, Peter. Abertura: a nova história, seu passado e seu futuro. In: Burke, Peter. (org.) A escrita da história: novas perspectivas. São Paulo: UNESP, 1992.

CHARTIER, R. A história cultural. Entre práticas e representações. Lisboa: DIFEL, 1990. Tradução: Maria Manuela Galhardo.

CUNHA, Olívia Maria Gomes. Tempo imperfeito: uma etnografia do arquivo. MANA 10(2):287-322, 2004.

FAUSTO, Boris. Crime e Cotidiano em São Paulo (1880 - 1924). São Paulo: Brasiliense, 1984.

FOUCAULT, Michel. Vigiar e punir: história do nascimento das prisões. Petrópolis: Vozes, 1999.

FREIRE, Cristina. I Seminário Internacional de Arquivos de Museu e Pesquisa. MAC-USP/Pinacoteca do Estado, Campus Universitário da Capital, 2009.

MEGALE, Heitor \& TOLEDO NETO, Silvio. Por minha letra e sinal: documentos do ouro do século XVII. Cotia: Ateliê, 2006.

NASCIMENTO, Aires Augusto. Práticas codicológicas e sentido de enquadramento do livro manuscrito como produto cultural. Colóquio sobre livro antigo, Actas, 1988.

NATIVIDADE, Marcelo Tavares. Margens da política: direitos sexuais, Estado e religiões. Rio de Janeiro: Garamond, 2015.

NOGUEIRA SOUSA, Clementino. Entre a vida e a morte no jogo das paixões - mulheres e homens no espaço urbano de Cuiabá Sec. XIX. Dissertação. [Mestrado em História]. Universidade Federal de Mato Grosso UFMT. Cuiabá, 2001.

PALERMO, Miguel. Nioaque: evolução política e revolução de Mato Grosso. Campo Grande: Tribunal de Justiça de Mato Grosso, 1992.

PERARO, Maria Adenir. Fardas, saias e batina. A ilegitimidade na paróquia bom Jesus de Cuiabá (1853-1890). Tese [Doutorado em História]. Universidade Federal do Paraná, 1997.

PERROT, M. Os excluídos da História: operários, mulheres, prisioneiros. Rio de Janeiro: Paz e Terra, 1988. QUEIROZ, Maria Isaura Pereira. O mandonismo local na vida política brasileira e outros ensaios. São Paulo: Alfa-Omega, 1976.

RODRIGUES, Marinete A. Z. Justiça nas relações de conflitos em Mato Grosso no século XIX. XIX Encontro Regional de História: Poder, Violência e Exclusão. ANPUH/SP - USP, 2008a.

Criminalidade e relações de poder em Mato Grosso (1870-1910). Dissertação. [Mestrado em História e Sociedade]. FCL/UNESP:Assis/SP, 2008b.

Mulheres, violência e justiça: crime e criminalidade no sul de Mato Grosso, 1830 a 1889. Tese (Doutorado em História). FFLCH/USP, 2013. 
SANTIAGO-ALMEIDA, Manoel Mourivaldo. Os manuscritos e impressos antigos: a via filológica. In: Modelos de Análise Linguística. Organização de Beatriz Daruj Gil; Valeria Gil Condé e Elis de Almeida Cardoso. São Paulo: Contexto, 2009.

SPAGNOL, Sergio. Desejo Marginal: violência nas relações homossexuais. São Paulo: Arte \& Ciência, 2001.

SPINA, Segismundo. Introdução à edótica. São Paulo: Cultrix/ USP, 1977.

TOURINHO FILHO, Fernando da Costa. Processo Penal. Processo Penal, volume I. 31 ed. rev. e atual. São Paulo: SARAIVA, 2009.

VILLARRUEL-SILVA, Mário Luis. Violência interpessoal e ordem policial no cotidiano de mulheres da Província de Mato Grosso. Edições facsimilar e semidiplomática de autos crimes. Dissertação (Mestrado em Filologia). Faculdade de Filos., Letras e Ciências Humanas - Universidade de São Paulo - FFLCH/USP. 2011.

VILLARRUEL-SILVA, Mário Luis \& MOTA, Ana Claudia A. A. O léxico filológico. Revista Metalinguagens, São Paulo: IFSP. n. 04, nov. 2015.

VOLPATO, Luiza R. R. A conquista da terra no universo da pobreza. São Paulo: HUCITEC / INL, 1987.

Cativos do Sertão. Tese. [Doutorado em História Social]. Faculdade de Filosofia, Letras e C. Humanas da Universidade de São Paulo - FFLCH/ USP, 1991.

XAVIER, Lidia de Oliveira. Fronteira oeste brasileira: entre o contraste a integração. Tese de Doutorado [História]. Universidade de Brasília - UNB, Brasília, 2006.

WOJCIECHOWSKI, Eula. "Sem lei nem rei": debochados, vadios e perniciosos. Os soldados militares na Província de Mato Grosso, 1850 a 1864. Dissertação. [Mestrado em História]. Universidade Federal de Mato Grosso-UFMT, Cuiabá, 2004.

WOLKMER, Antonio Carlos. História do Direito no Brasil. 2a Edição. Rio de Janeiro: Forense, 1999.

Trabalho enviado em 11 de maio de 2016.

Aceito em 24 de julho de 2016. 